\title{
A hybrid technique for treating multilevel cervical myelopathy: Cervical artificial disc replacement combined with fusion
}

\author{
YUNRONG ZHU ${ }^{1}$, JIANFENG FANG ${ }^{1}$, GUOHUA XU $^{2}$, XIAOJIAN YE $^{2}$ and YUNQING ZHANG ${ }^{1}$ \\ ${ }^{1}$ Department of Orthopedics, Jiangyin People's Hospital, Southeast University, Jiangyin, Jiangsu 214400; \\ ${ }^{2}$ Department of Orthopedics, Changzheng Hospital, Second Military Medical University, Shanghai 200003, P.R. China
}

Received April 9, 2018; Accepted October 5, 2018

DOI: $10.3892 / 01.2018 .9573$

\begin{abstract}
Clinical and radiographic outcomes of multilevel cervical myelopathy (MCM) patients treated with a hybrid technique combining cervical anterior corpectomy and fusion (ACF) with cervical artificial disc replacement (C-ADR) were evaluated. A total of 23 patients including 14 females and 9 males (mean age, 48.3 years) were treated with the hybrid technique and they were followed up for an average time of 35 months (range from 24 to 40 months). Arm- and neck-pain visual analogue scale (VAS) scores, neck disability index (NDI) scores and C2-7 range of motion (ROM) preoperation and 6 weeks, 3 and 24 months postoperation were assessed and compared. Fusion success and system failure based on anteroposterior (AP), lateral and flexion/extension X-rays were examined by an independent reviewer. Postoperative VAS, NDI and ROM were decreased significantly at all the time-points examined, as compared to preoperative scores $(\mathrm{P}<0.05)$. The results revealed that this hybrid technique is both technically feasible and effective for the treatment of MCM. However, future comparative studies will be required to determine the potential benefits and pitfalls of this hybrid technique.
\end{abstract}

\section{Introduction}

Cervical anterior corpectomy and fusion (ACF), which involves direct removal of the compressive abnormality with stabilization obtained by anterior arthrodesis, has been used as a standard treatment option for cervical disc disease with excellent clinical outcomes (1). However, there are some limitations

Correspondence to: Dr Xiaojian Ye, Department of Orthopedics, Changzheng Hospital, Second Military Medical University, 415 Fengyang Road, Shanghai 200003, P.R. China

E-mail: yexj1964@hotmail.com

Dr Yunqing Zhang, Department of Orthopedics, Jiangyin People's Hospital, Southeast University, 163 Shoushan Road, Jiangyin, Jiangsu 214400, P.R. China

E-mail: zhangspine@163.com

Key words: hybrid technique, multilevel cervical myelopathy, clinical and radiographic outcomes, retrospective study to ACF. First of all, for $25 \%$ of the patients undergoing cervical fusion, the symptoms will reappear within 10 years (2). It has been well documented that the rate of pseudarthrosis increases with each segmental level added to an anterior decompression and fusion (3). Secondly, although ACF has been employed to treat cervical myelopathy caused by soft disc herniation with stable outcomes (4), complications related to bone grafting, such as dislodgement, fracture, and nonunion of the grafted bone (5), and recurrence of myelopathy due to adjacent segment degeneration (6) have been reported. So in some cases, more than three-levels of ACF (7) or cervical disc replacement have to be performed to avoid secondary myelopathy.

The complications associated with ACF could potentially be minimized by combining ACF with other treatments, such as cervical artificial disc replacement (C-ADR). Analysis of the strain distribution of intervertebral discs after ACF showed an increase in longitudinal strain, most frequently at the levels immediately adjacent to the fused level (8). On the other hand, it has been demonstrated that C-ADR maintains motion at the operated level and decreases strain on the adjacent segments for prevention of adjacent-segment disease (ASD) (9). Therefore, $\mathrm{ACF}$ and $\mathrm{C}$-ADR could potentially be combined together to treat multilevel cervical myelopathy (MCM) with reduced risk of ASD. Since the clinical outcomes of two levels C-ADR are not well defined, in this study we only performed one level C-ADR on the patients. Our current study aimed to evaluate the clinical and radiographic outcomes of patients undergoing this hybrid technique.

\section{Patients and methods}

Patient data. All patients with MCM undergoing this hybrid technique in the authors' clinic over a 3-year period were assessed. This study was approved by the Ethics Committee of Jiangyin People's Hospital (Jiangyin, China) and Changzheng Hospital (Shanghai, China). Signed written informed consents were obtained from all participants before the study. Inclusion criteria: patients with three or four consecutive level degenerative disc disease between $\mathrm{C} 3$ and $\mathrm{C} 7$ and with a radiculopathy or myelopathy that was not responding to conservative treatments. Exclusion criteria: facet syndrome, patients with stenosis caused by posterior compression, osteoporosis, ossification of posterior longitudinal ligament (OPLL), tumor, severe degenerative scoliosis or kyphosis and infection, which 


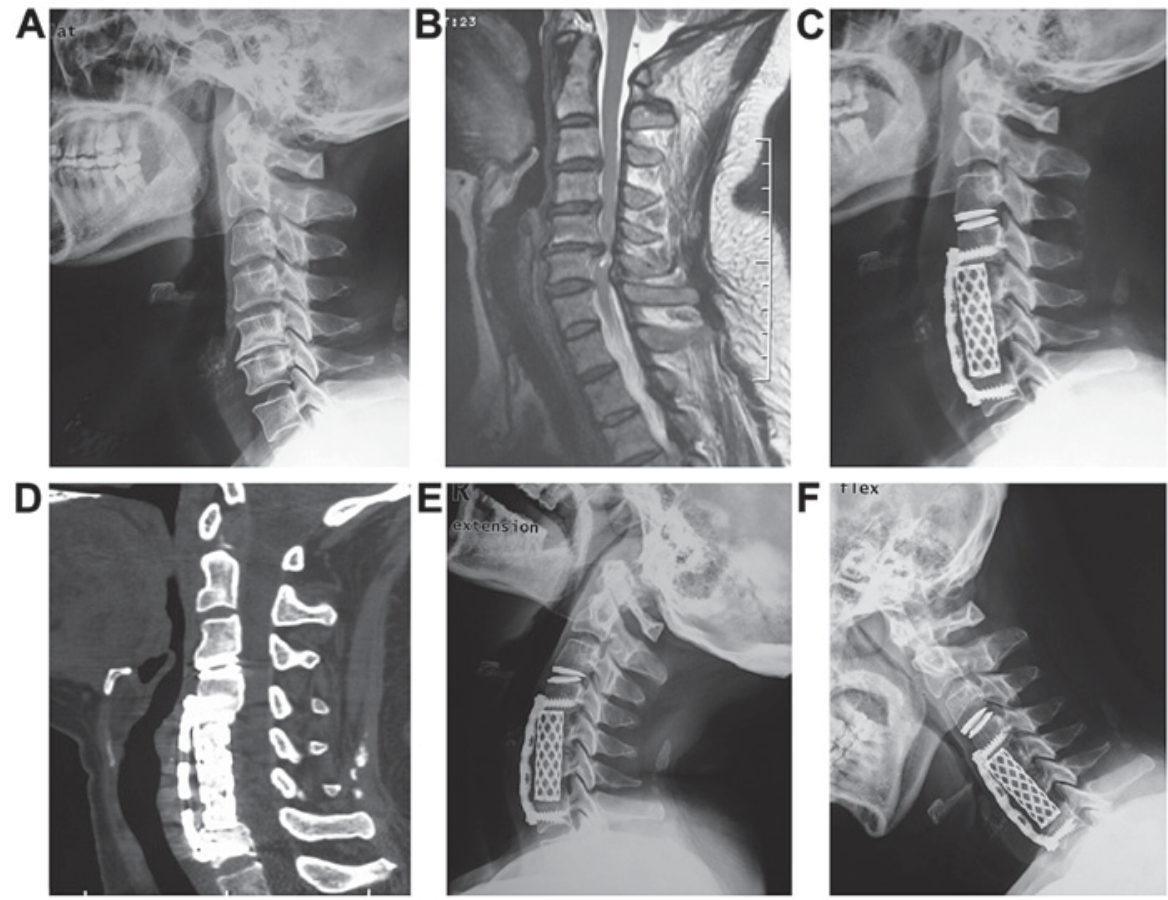

Figure 1. Pre- and postoperative images. (A) Lateral C spine X-ray showing spondylotic changes in the C3-4, 4-5, 5-6 and 6-7 intervertebral disc spaces; (B) preoperative sagittal T2-weighted image which shows that the spinal cord was compressed by C3/4, 4/5, 5/6 and 6/7 discs; (C) postoperative outcome after performing ACF of C5-6 and C-ADR of C3/4; (D) the operated level after fusion performed at 6 months postoperation; (E and F) postoperative 2-year cervical dynamic radiographs show preserved ROM of C2-7. ACF, anterior corpectomy and fusion; C-ADR, cervical artificial disc replacement; ROM, range of motion.

are considered as the standard contraindications for ACF and C-ADR techniques. Hybrid technique was not performed if the first or the last segment was spondylotic and not mobile. A total of 23 patients (14 females and 9 males) were included in the study. The mean age at surgery was $48.3 \pm 8.5$ years. The target levels were consecutive in all cases, including C3-6 $(n=9), C 3-7(n=6), C 4-7(n=8)$. C-ADR was performed in the segment that had greater physiologic motion $(\mathrm{C} 6 / 7>\mathrm{C} 3 / 4)$ when the first or the last segment was mobile and non-spondylotic.

Surgical procedure. A standard Smith-Robinson approach was used to expose the symptomatic levels in all patients. Subtotal corpectomy with strut graft was performed by removing discs, vertebral bodies, and posterior longitudinal ligament (10). Operative levels were determined based on preoperative radiographic results. Extensive decompression was performed to expose the dura throughout the length of the corpectomy and discectomy via removal of the osteophytes, herniated nucleus pulposus and posterior longitudinal ligament. Titanium mesh (DePuy Synthes Spine, Inc., Raynham, MA, USA) filled with the bone dust of the resected vertebra was placed in the anterior cervical plate (Slim-Loc; DePuy Synthes Spine, Inc.). Preparation of the endplates for arthroplasty was accomplished following the standard procedure. Sizing of the Prestige ${ }^{\circledR}$ Cervical Disc (Medtronic, Memphis, TN, USA) was determined by comparing the preoperative radiographic results including computed tomography (CT) scan to the templates. Insertion of the C-ADR (Discover ${ }^{\mathrm{TM}}$; DePuy Synthes Spine, Inc.) was accomplished under lateral fluoroscopy to ensure adequate depth. Correct placement of a C-ADR was confirmed by anteroposterior (AP) and lateral fluoroscopic imaging before closure of the incision. All patients were allowed to sit up within a few days after surgery and wore a plastic cervical collar without a chin support for 2 months.

Data collection. Preoperative demographic, surgical, and outcome data were collected from all patients. Clinical outcomes were assessed by arm and neck VAS scores, neck disability index (NDI) scores and range of motion (ROM). ROM of the cervical spine was measured on plain radiographs. Data from patients who had completed the follow-up examination scheduled at 6 weeks, 3 and 24 months after surgery were analyzed.

Statistical analysis. Statistical Package for the Social Sciences (SPSS) program (version 11.0; SPSS, Inc., Chicago, IL, USA) was used for the statistical analyses. Results are expressed as mean \pm standard deviation (SD). Comparison between multiple groups was made using one-way ANOVA followed by a post-hoc test (Least Significant Difference). $\mathrm{P}<0.05$ was considered to indicate a statistically significant difference.

\section{Results}

Correct placement of $C$-ADR. To make sure that C-ADR was correctly placed during the surgery, lateral fluoroscopic images were taken as shown in Fig. 1A. No hardware complications were observed in this study as shown in Fig. 1C. Bone fusion was achieved in all patients at 6 months after operation (Fig. 1D). ROM was calculated by the difference in Cobb angles between full flexion and extension in lateral cervical radiographs (Fig. 1).

Clinical outcomes. As shown in Fig. 2, the neck-pain VAS score before surgery was $6.96 \pm 1.77$, and decreased gradually 
Table I. The C2-7 ROM decrease for anterior surgery in each study.

\begin{tabular}{|c|c|c|c|c|c|c|}
\hline \multirow[b]{2}{*}{ Sources } & \multirow[b]{2}{*}{ Approach } & \multirow[b]{2}{*}{ Follow-up time } & \multirow[b]{2}{*}{ No. of patients } & \multicolumn{2}{|c|}{$\begin{array}{l}\text { Cervical ROM } \\
\text { (degree) }\end{array}$} & \multirow{2}{*}{$\begin{array}{c}\text { Mean } \\
\text { decrease rate } \\
\text { of ROM }(\%)\end{array}$} \\
\hline & & & & Pre- & Post- & \\
\hline Edwards et al (10) & $\begin{array}{l}\text { Corpectomy and fusion } \\
\text { with instrumentation }\end{array}$ & 49 months & 13 & 37.00 & 16.00 & 56.76 \\
\hline Wada et al (11) & $\begin{array}{l}\text { Corpectomy and fusion } \\
\text { without instrumentation }\end{array}$ & 15 years & 23 & 39.40 & 19.20 & 51.27 \\
\hline Lee et al (12) & $\begin{array}{l}\text { Corpectomy and fusion } \\
\text { with instrumentation }\end{array}$ & 21.8 months & 20 & 37.30 & 17.70 & 52.55 \\
\hline
\end{tabular}

ROM, range of motion.

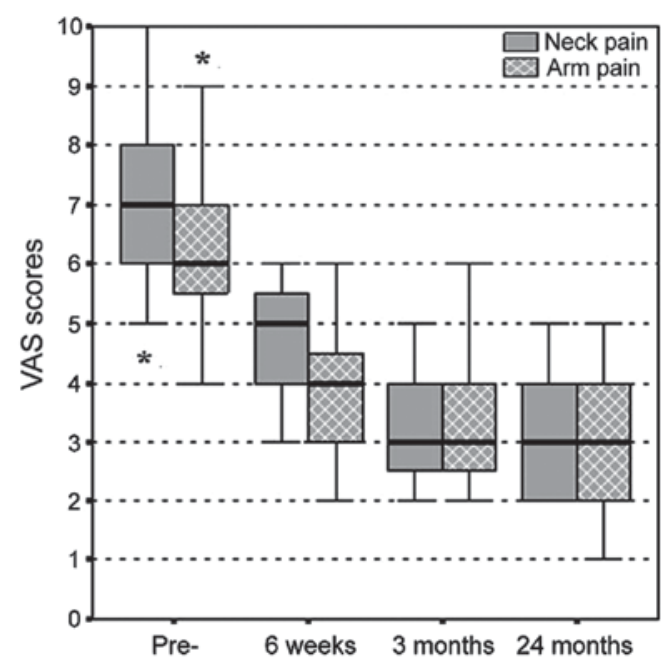

Figure 2. Neck- and arm-pain VAS scores before operation and at follow-up time-points of 6 weeks, 3 and 24 months ( $(\mathrm{P}<0.05)$. VAS, visual analogue scale.

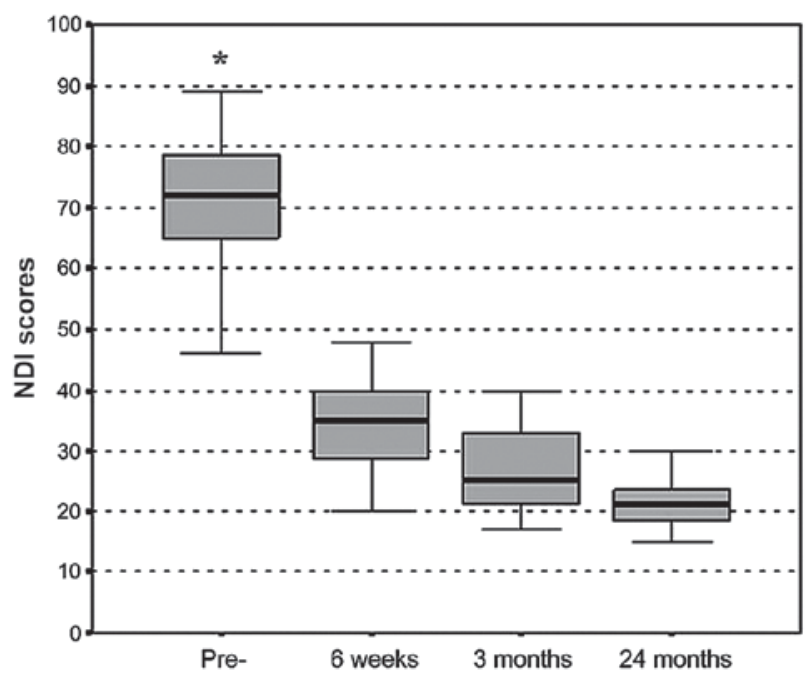

Figure 3. NDI scores before operation and at follow-up time-points of 6 weeks, 3 and 24 months ( $(\mathrm{P}<0.05)$. NDI, neck disability index.

over the follow-up period $(4.65 \pm 1.03$ at 6 weeks; $3.30 \pm 1.06$ at 3 months and $3.09 \pm 0.95$ at 24 months). The same trend was

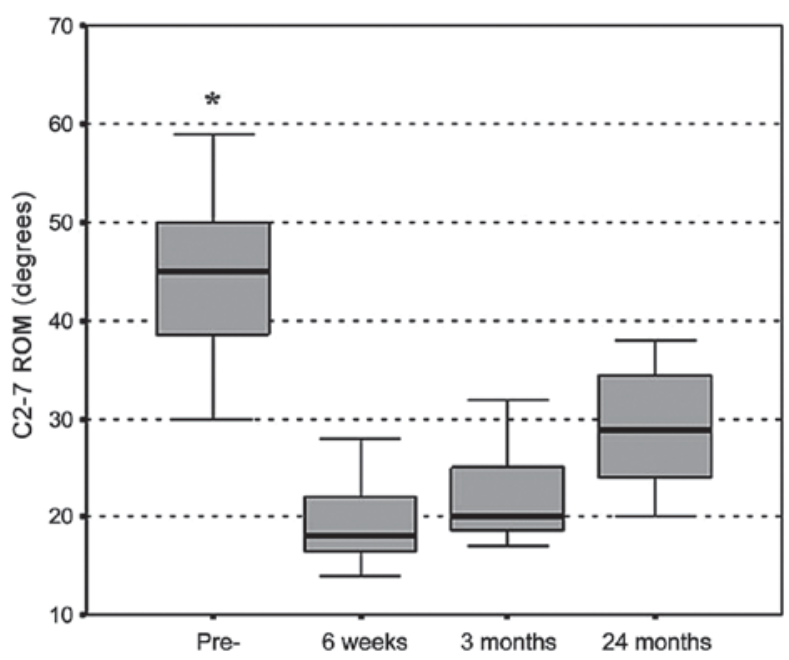

Figure 4. The C2-7 ROM before operation and at follow-up time-points of 6 weeks, 3 and 24 months ( $(\mathrm{P}<0.05)$. ROM, range of motion.

observed for arm-pain VAS score, which was $6.35 \pm 1.61$ before surgery and decreased to $4.00 \pm 1.13$ at 6 weeks; $3.30 \pm 1.11$ at 3 months and $3.00 \pm 0.95$ at 24 months after surgery. Therefore, our results showed that both the neck- and arm-pain VAS scores were significantly improved after surgery $(\mathrm{P}<0.05)$.

Reduction of NDI scores was also observed after surgery at all follow-up time-points $(70.39 \pm 10.68$ before surgery vs. $37.65 \pm 13.59$ at 6 weeks; $26.65 \pm 6.87$ at 3 months and $21.35 \pm 4.09$ at 24 months after surgery) (Fig. 3). The differences between pre- and postoperative NDI scores were statistically significant $(\mathrm{P}<0.05)$.

Changes in C2-7 ROM were also notable (Fig. 4). We observed a $56 \%$ of reduction in ROM at 6 weeks after surgery $(43.96 \pm 8.19$ vs. $19.17 \pm 3.55, \mathrm{P}<0.05)$. The reduction rate of ROM was less as the follow-up prolonged (50\% at 3-month follow-up and 34\% at 24-month follow-up), but the statistical significance remained $(\mathrm{P}<0.05)$. The $\mathrm{C} 2-7$ ROM degrees achieved by our hybrid technique were compared to the data from some of the published studies which assessed anterior or posterior approach in MCM (Table I) (10-12). Studies (10-12) showed that the rate of the ROM decrease was greater than those obtained by this hybrid technique. 
Surgical outcomes and complications. During the follow-up period, there were no complications related to the surgical procedures, such as device migration, infection, neurologic compromise, pseudoarthrosis, or heterotopic ossification. No other adjacent segment degeneration was detected either radiographically or clinically.

\section{Discussion}

The primary goals of the surgical treatment of MCM are the relief of neurological compression, stabilization of cervical spine and restoration of lordotic alignment. Posterior procedures, such as laminectomy and laminoplasty, which are associated with significant postoperative axial pain and high incidence of postoperative kyphosis, have become less preferred treatments of MCM $(2,13,14)$. For patients with cervical myelopathy involving only one or two motion segments, ACF has been the preferred surgical treatment which is performed with high success rate and less complications (15). However ACF is not the best treatment option for MCM involving three or more levels, as it is associated with less predictable outcomes and a higher frequency of complications $(16,17)$. So, currently, the most commonly used technique for MCM with three or more levels is contiguous corpectomies and fusion. However, the incidence of complications resulting from this surgical modality, such as graft displacement, non-union and hardware-related complications, is increased as more levels are decompressed $(8,18-20)$. It has been demonstrated that a two-level fusion substantially increases intradiscal pressure as compared to single-level fusion. Hilibrand et al (21) have recommended that all degenerated adjacent segments should be fused with the target level. It has been demonstrated that $\mathrm{C}$-ADR maintains motion at the operated level and decreases strain on the adjacent segments for prevention of ASD (22-24). If the level at which surgery was performed still maintains mobility, compensatory hypermobility may not occur in adjacent levels (2). In MCM with sufficient cervical motion at one or two levels, hybrid technique combining C-ADR at the mobile level, with ACDF at the spondylotic level, may be a reasonable alternative to contiguous corpectomies and fusion.

One of the open questions regarding the hybrid technique as used in this study is whether or not combination of $\mathrm{ACF}$ with C-ADR leads to firm fusion. In the present study, our radiographic evaluation demonstrated a $100 \%$ fusion rate in the segments. This hybrid technique was effective in eliminating radicular pain and had a favorable recovery of NDI scores. At 6 weeks, the C2-7 ROM decreased immediately after surgery because of patients' fear and residual pain. As the fear and residual pain alleviated, the C2-7 ROM showed a better recovery at 3 and 24 months. On the other hand, we assumed that preserved ROM may be the basis for a better clinical outcome. Our results are in close agreement with previous research comparing clinical and radiological outcomes between artificial disc replacement and fusion. Also incidences of complications and secondary operations in the current study are low, suggesting the functional success of this hybrid technique. Hilibrand et al (21) have reported that each year $2.9 \%$ of the patients has to go through surgery due to symptomatic ASD after ACF. In our present study, we did not observe any cases of ASD. We hypothesize that the hybrid technique can reduce ASD by reducing hypermobility in adjacent segments, or the small sample size and the short follow-up periods are responsible for this result. Shin et al (25) have reported that in two consecutive level cervical disc disease, the hybrid technique is superior to the two-level ACDF in terms of better NDI recovery, less postoperative neck pain, faster $\mathrm{C} 2-7$ ROM recovery, and less adjacent ROM. But these benefits of hybrid technique are similar to those of 2-ACDF with 5 years of follow-up (26).

Further studies are required to determine the underlying etiology of adjacent segment degeneration which might be due to the type of instrumentation used or the natural history of the disease itself. Also, it would be beneficial to understand the ideal biomechanical properties of this hybrid technique, which would enable us to make better use of this hybrid technique in treating MCM patients.

High hospitalization expenses, small sample size, short follow-up period and lack of a control group are the few limitations of the present study.

In conclusion, the results in this study indicate that this hybrid technique treatment combining ACDF with C-TDR is both technically feasible and effective for surgical treatment of MCM. This study demonstrates the benefits of developing a treatment specific for the needs of the patient and each vertebral segment. However, future comparative studies will be required to determine the potential pros and cons of the hybrid technique. Long-term follow-up studies are also required to assess the clinical and functional outcome, and reoperation rates of the hybrid technique.

\section{Acknowledgements}

Not applicable.

\section{Funding}

This study was supported by the Young Medical Talents of Jiangsu Province (QNRC2016132), and the Major Program of Wuxi Municipal Commission of Health and Family Planning (201708).

\section{Availability of data and materials}

All data generated or analyzed during this study are included in this published article.

\section{Authors' contributions}

YZhu and YZhang designed the study and performed the experiments; JF, GX and XY collected the data; JF and GX analyzed the data; YZhu and XY prepared the manuscript. All authors read and approved the final manuscript.

\section{Ethics approval and consent to participate}

This study was approved by the Ethics Committee of Jiangyin People's Hospital (Jiangyin, China) and Changzheng Hospital (Shanghai, China). Signed written informed consents were obtained from all participants before the study. 


\section{Patient consent for publication}

Not applicable.

\section{Competing interests}

The authors declare that they have no competing interests.

\section{References}

1. Bose B: Anterior cervical fusion using Caspar plating: Analysis of results and review of the literature. Surg Neurol 49: 25-31 1998.

2. Hilibrand AS, Carlson GD, Palumbo MA, Jones PK and Bohlman HH: Radiculopathy and myelopathy at segments adjacent to the site of a previous anterior cervical arthrodesis. J Bone Joint Surg Am 81: 519-528, 1999.

3. Farey ID, McAfee PC, Davis RF and Long DM: Pseudarthrosis of the cervical spine after anterior arthrodesis. Treatment by posterior nerve-root decompression, stabilization, and arthrodesis. J Bone Joint Surg Am 72: 1171-1177, 1990.

4. Kokubun $\mathrm{S}$ and Sato T: (ii) Cervical myelopathy and its management. Curr Orthop 12: 7-12, 1998.

5. Yonenobu K, Fuji T, Ono K, Okada K, Yamamoto T and Harada N: Choice of surgical treatment for multisegmental cervical spondylotic myelopathy. Spine 10: 710-716, 1985

6. Odate S, Shikata J, Soeda T, Yamamura S and Kawaguchi S: Surgical results and complications of anterior decompression and fusion as a revision surgery after initial posterior surgery for cervical myelopathy due to ossification of the posterior longitudinal ligament. J Neurosurg Spine 26: 466-473, 2017.

7. Ikenaga M, Shikata J and Tanaka C: Long-term results over 10 years of anterior corpectomy and fusion for multilevel cervical myelopathy. Spine 31: 1568-1574, 2006.

8. Schwab JS, Diangelo DJ and Foley KT: Motion compensation associated with single-level cervical fusion: Where does the lost motion go? Spine 31: 2439-2448, 2006.

9. Yi S, Shin HC, Kim KN, Park HK, Jang IT and Yoon DH: Modified techniques to prevent sagittal imbalance after cervical arthroplasty. Spine 32: 1986-1991, 2007.

10. Edwards CC II, Heller JG and Murakami H: Corpectomy versus laminoplasty for multilevel cervical myelopathy: An independent matched-cohort analysis. Spine 27: 1168-1175, 2002.

11. Wada E, Suzuki S, Kanazawa A, Matsuoka T, Miyamoto S and Yonenobu K: Subtotal corpectomy versus laminoplasty for multilevel cervical spondylotic myelopathy: A long-term follow-up study over 10 years. Spine 26: 1443-1447, 2001.

12. Lee SH, Ahn Y and Lee JH: Laser-assisted anterior cervica corpectomy versus posterior laminoplasty for cervical myelopathic patients with multilevel ossification of the posterior longitudinal ligament. Photomed Laser Surg 26: 119-127, 2008.
13. Herkowitz HN: A comparison of anterior cervical fusion cervical laminectomy, and cervical laminoplasty for the surgical management of multiple level spondylotic radiculopathy. Spine 13: 774-780, 1988

14. Yonenobu K, Hosono N, Iwasaki M, Asano M and Ono K: Laminoplasty versus subtotal corpectomy. A comparative study of results in multisegmental cervical spondylotic myelopathy. Spine 17: 1281-1284, 1992.

15. Saunders RL, Pikus HJ and Ball P: Four-level cervical corpectomy. Spine 23: 2455-2461, 1998

16. Vaccaro AR, Falatyn SP, Scuderi GJ, Eismont FJ, McGuire RA, Singh K and Garfin SR: Early failure of long segment anterior cervical plate fixation. J Spinal Disord 11: 410-415, 1998.

17. Chen Y, Chen D, Guo Y, Wang X, Lu X, He Z and Yuan W: Subsidence of titanium mesh cage: A study based on 300 cases. J Spinal Disord Tech 21: 489-492, 2008.

18. Hee HT, Majd ME, Holt RT, Whitecloud TR and Pienkowski D Complications of multilevel cervical corpectomies and reconstruction with titanium cages and anterior plating. J Spinal Disord Tech 16: 1-8, 2003.

19. Majd ME, Vadhva M and Holt RT: Anterior cervical reconstruction using titanium cages with anterior plating. Spine 24 : 1604-1610, 1999

20. Nakase H, Park YS, Kimura H, Sakaki T and Morimoto T: Complications and long-term follow-up results in titanium mesh cage reconstruction after cervical corpectomy. J Spinal Disord Tech 19: 353-357, 2006.

21. Hilibrand AS, Yoo JU, Carlson GD and Bohlman HH: The success of anterior cervical arthrodesis adjacent to a previous fusion. Spine 22: 1574-1579, 1997.

22. Dmitriev AE, Cunningham BW, Hu N, Sell G, Vigna F and McAfee PC: Adjacent level intradiscal pressure and segmental kinematics following a cervical total disc arthroplasty: An in vitro human cadaveric model. Spine 30: 1165-1172, 2005.

23. Emery SE, Bohlman HH, Bolesta MJ and Jones PK: Anterior cervical decompression and arthrodesis for the treatment of cervical spondylotic myelopathy. Two to seventeen-year follow-up. J Bone Joint Surg Am 80: 941-951, 1998.

24. Robertson JT, Papadopoulos SM and Traynelis VC: Assessment of adjacent-segment disease in patients treated with cervical fusion or arthroplasty: A prospective 2-year study. J Neurosurg Spine 3: 417-423, 2005.

25. Shin DA, Yi S, Yoon DH, Kim KN and Shin HC: Artificial disc replacement combined with fusion versus two-level fusion in cervical two-level disc disease. Spine 34: 1153-1159, 2009.

26. Ji GY, Oh CH, Shin DA, Ha Y, Yi S, Kim KN, Shin HC and Yoon DH: Artificial disk replacement combined with fusion versus 2-level fusion in cervical 2-level disk disease with a 5-year follow-up. Clin Spine Surg 30: E620-E627, 2017.

This work is licensed under a Creative Commons Attribution-NonCommercial-NoDerivatives 4.0 International (CC BY-NC-ND 4.0) License. 